\title{
Marcas Populares e Reposicionamento de Moda: análise das estratégias de comunicação
}

Richard Perassi Luiz de Sousa

Doutor em Comunicação e Semiótica pela Pontifícia Universidade Católica de São Paulo/ richard.perassi@uol.com.br

Orcid: 0000-0003-0696-4110/ lattes 


\title{
Marcas Populares e Reposicionamento de Moda: análise das estratégias de comunicação
}

\author{
RESUMO \\ Este artigo aborda as estratégias de comunicação do \\ reposicionamento de Moda das marcas populares de \\ vestuário e acessórios. O objetivo é propor uma \\ sistematização do conjunto de estratégias verificadas na \\ comunicação pública das marcas C\&A, Lojas Renner, Marisa \\ e Riachuelo. Trata-se de parte dos resultados de uma \\ pesquisa qualitativa, de objetivos exploratórios e descritivos, \\ com base na consulta de fontes documentais na rede digital \\ internet. Os resultados apontam que as estratégias, ações, \\ recursos e discursos aplicados pelas marcas estudadas \\ podem ser sistematizados em três estratégias básicas: (1) \\ sistema fast fashion; (2) co-branding e associações com o \\ sistema de moda; (3) e investimento em lojas especiais. \\ Cada estratégia básica é suportada por uma série de ações \\ complementares que, em conjunto, promovem a associação \\ das marcas populares com a cultura de moda.
}

Palavras-chave: Moda Popular; Comunicação de Marca; Fast fashion. 


\title{
Popular Brands and Fashion Repositioning: an analysis of the communication strategies
}

\begin{abstract}
The communication strategies applied by the apparel and accessories popular brands to repositioning as Fashion brands are addresses in this paper. The goal is to propose a systematization of the series of strategies used in the public communication of the brands C\&A, Lojas Renner, Marisa and Riachuelo. The study presents part of the results of a qualitative research, with exploratory and descriptive goals, based on documentary sources in the internet. As results, the strategies, actions, resources and speeches used by the popular brands can by systematized in three basic strategies: (1) fast fashion system; (2) co-branding and association with the fashion system; and (3) investment in special stores. Each basic strategy is supported by a series of complementary actions that, in interaction, promote the association of the popular brands with the Fashion culture.
\end{abstract}

Keywords: Popular fashion; Brand Repositioning; Fast fashion. 


\title{
Marcas Populares y Reposicionamiento de Moda: análisis de la estrategia de comunicación
}

\begin{abstract}
RESUMEN
Este artículo analiza las estrategias de comunicación de reposicionamiento de moda de marcas populares de ropa y accesorios. El objetivo es proporcionar una sistematización del conjunto de estrategias de comunicación pública de las marcas C\&A, Lojas Renner, Marisa y Riachuelo. Se discuten dos resultados de una investigación cualitativa, con objetivos exploratorios y descriptivos, basados en la consulta de fuentes documentales en internet digital. Los resultados indican que las estrategias, acciones, recursos y discursos aplicados a las marcas estudiadas pueden sistematizarse en tres estrategias básicas: (1) sistema de moda rápida; (2) marca compartida y afiliaciones con el sistema Fashion; (3) e inversión en tiendas especiales. Cada estrategia básica está respaldada por una serie de acciones complementarias que juntas promocionan marcas populares asociadas con la cultura de la moda.
\end{abstract}

Palabras clave: Moda popular; Comunicación de marca; Fast fashion. 


\section{INTRODUÇÃO}

Para a cultura atual de mercado, o conceito de moda é um ativo intangível que possui forte apelo, sendo do interesse de gestores de diferentes segmentos de marcas estabelecerem uma associação dos seus produtos e serviços com o valor de moda. No segmento de varejo de vestuário e acessórios, em especial, o conceito de moda atribui valores estético-simbólicos que posicionam os produtos de modo diferenciado no mercado (EUZÉBIO; VIEIRA; PERASSI, 2011). Portanto, grifes de vestuário e acessórios são tradicionalmente posicionadas e reconhecidas como marcas de moda.

A partir do final da década de 1990, gestores de lojas populares de vestuário e acessórios atuantes no mercado brasileiro, gradualmente, fortaleceram a associação de suas marcas com o conceito de moda. Redes de lojas que anteriormente enfatizavam a boa relação entre custo e benefício de seus produtos, passaram a almejar o posicionamento de 'marcas populares de moda', como resposta às transformações socioeconômicas ocorridas no país, especialmente em relação ao público consumidor popular.

A ascensão social da classe C brasileira, naquele período, repercutiu em mudanças nos hábitos de consumo deste grupo, permitindo o acesso a bens antes restritos à classe média, gerando uma demanda de mercado inexistente há anos (SCALFI; BARRIZZELLI, 2012; REIS, 2012). Outro motivo que despertou o interesse em produtos de moda nos grupos populares foi a facilitação ao acesso à informação. Deste contexto, resulta um consumidor popular bem informado acerca das tendências de moda e, consequentemente, exigente, pois verifica preço, qualidade e sofisticação das lojas (BRIDI; PERERA, 2014). 
Alguns autores apontam o reposicionamento das redes populares de vestuário e acessórios também como uma tentativa de atingir consumidores de maior poder aquisitivo (CRUZ-MOREIRA, 2003; TUBAKI; LIMA, 2014; MESSIAS, 2015). O reposicionamento de moda foi observado em grandes redes de lojas de atuação nacional, como C\&A, Lojas Renner, Marisa e Riachuelo, e também em empresas de menor porte e atuação regional.

No âmbito das grandes redes, atuantes em todo o país, a empresa holandesa $C \& A$ reposicionou sua oferta no final da década de 1990. A marca buscou se distanciar do conceito de popular e barato, e penetrar em classes com maior poder aquisitivo por meio de uma aproximação de um conceito 'fashion' e sofisticado, mas mantendo os preços acessíveis. O bem sucedido reposicionamento da C\&A levou redes concorrentes a estabelecerem estratégias similares (TELLES, 2004).

A rede de lojas Riachuelo, anteriormente focada na venda de alto volume de produtos industrializados, de qualidade e preços acessíveis, a partir dos anos 2000, passou a ofertar produtos com apelo às tendências e estilos da moda (SILVA, 2011). O posicionamento da rede de lojas Marisa, tradicionalmente focado nos preços imbatíveis (GARCIA, 2001), também foi alterado no fim da década de 1990 e início de 2000, destacando, a partir de então, a comercialização de estilos de vida, e não mais commodities (REIS, 2012). A gestão da rede de lojas Renner adotou a estratégia fast fashion em 2004, quando passou a lançar minicoleções quinzenais (LOJAS RENNER, 2016).

O objetivo deste artigo é propor uma sistematização das estratégias de reposicionamento de moda verificadas na comunicação pública das marcas populares citadas. Estas foram evidenciadas a partir de recorrências nas estratégias, ações, recursos e discursos adotados pelas marcas 
estudadas. Trata-se de parte dos resultados de uma pesquisa qualitativa, de objetivos exploratórios e descritivos e consulta a fontes documentais com base na rede digital Internet, que incluíram websites e redes sociais das marcas em estudo, bem como outros weblogs e websites de diversas naturezas.

O artigo estrutura-se de modo que, inicialmente, são apresentados os referenciais teóricos que fundamentam o estudo, seguidos da descrição do conjunto de estratégias de reposicionamento de moda tomadas pelas marcas populares estudadas. Após, são apresentados os resultados, que configuram a sistematização do conjunto de estratégias em três bases: (1) fast fashion; (2) co-branding e associações com elementos e agentes do sistema de moda; e (3) investimento em lojas especiais; bem como ações complementares que suportam cada estratégia básica e, em interação, promovem a associação das marcas populares com a cultura de moda.

\section{REFERENCIAL TEÓRICO}

\subsection{Identidade, Imagem e Posicionamento de Marca}

A marca de uma entidade - que pode ser uma empresa, instituição, produto, serviço ou pessoa, entre outros - é composta por um conjunto expressivo de sinais físicos associado a um conjunto intangível de sentimentos, ideias e lembranças (PERASSI, 2015). O conjunto expressivo inclui todos os sinais que identificam, representam e comunicam a marca. Podem ser sinais visuais, como a assinatura visual e demais elementos da identidade visual, ou sinais sonoros, como uma melodia usada em campanhas publicitárias ou uma trilha sonora característica do ponto de venda. Também, um aroma particular aplicado nas lojas pode 
constituir uma marca olfativa, além da possibilidade de sabores ou texturas características da marca.

O conjunto expressivo da marca está no mundo físico. Já o conjunto significativo está na mente do público, sendo formado a partir de cada contato com as expressões da marca. Assim, com o tempo, todas as experiências relacionadas à marca, positivas ou negativas, constituem uma síntese mental de sensações, sentimentos e ideias. Portanto, uma marca compreende os sinais físicos que a representam, bem como o conjunto mental de associações que é resgatado cada vez que um indivíduo se depara com as expressões da marca.

Os conceitos de 'identidade de marca' e 'imagem de marca' são usados no âmbito das atividades de Gestão da Marca, ou Branding, para designar sínteses mentais de sensações, sentimentos e ideias associadas às expressões de uma entidade. A 'identidade de marca' se refere à síntese mental oficial, proposta pelos gestores da marca. Já a 'imagem de marca' é formada na mente do público externo à organização, a partir do contato com as expressões oficiais ou acidentais da marca. Como consequência, a 'imagem de marca' é menos previsível que a 'identidade de marca' (PERASSI, 2015).

O objetivo das atividades relacionadas à Gestão da Marca é disseminar uma imagem de marca positiva, tendo como base a consolidação da identidade oficial proposta pelos gestores. Assim, a comunicação da marca busca controlar, dentro do possível, todas as expressões relacionadas à marca, para que estas transmitam os conceitos, valores e atributos da identidade de marca (PERASSI, 2015).

É necessário salientar, como explica Semprini (2006), que apesar da tradicional distinção didática entre identidade e imagem de marca, a construção e a evolução da marca ocorrem de modo interativo entre o que é proposto pela 
organização e o público externo. Portanto, verifica-se que o processo de desenvolvimento da identidade recebe influências do público e do contexto em que está inserida, implicando na identidade de marca como resultado de uma troca de significados entre emissores e receptores.

Enquanto a identidade de marca representa atributos mais estáveis, ligados às raízes da marca, o conceito de posicionamento de marca deriva da identidade, mas aponta a um aspecto específico dela em determinado tempo, mercado e conjunto de competidores. O posicionamento explora as características que diferenciam uma marca das suas competidoras e os atributos que são atraentes para o público. Portanto, o posicionamento é delimitado pela competição de mercado e pode ser alterado com o tempo (KAPFERER, 2008).

Para Ries e Trout (2009), a necessidade de posicionar a marca decorre do excesso de estímulos comunicativos aos quais os consumidores são expostos. Conforme os autores, 0 posicionamento deve ser feito de modo a recorrer a algo que já existe na mente do consumidor, visto que a quantidade de informação continuamente recebida resulta na absorção apenas daquilo que ele já conhece ou foi anteriormente experienciado.

Aaker (2015) caracteriza o posicionamento como um guia de comunicação de curto prazo, que visa explicitar o que será comunicado, para qual público e empregando qual lógica. A mensagem de posicionamento está aberta a evoluções ou mudanças, com vistas a acompanhar as transformações do mercado ou capacidades organizacionais. O reposicionamento de marca, explica Telles (2004), se caracteriza como a redefinição dos elementos da identidade de marca a serem ativamente comunicados ao público. 


\subsection{A Promoção do Sistema de Moda}

Seguindo o objetivo do estudo, o recorte do sistema de moda tratado aqui inclui apenas os processos de promoção que visam legitimar a moda. Portanto, é adotada a definição de Kawamura (2005), que define moda como um sistema de instituições, organizações, grupos, produtores, eventos e práticas que, juntos, desenvolvem e expressam o conceito de moda.

Assim, Kawamura (2005) dá destaque aos profissionais de informação e comunicação, como designers ou estilistas, jornalistas e publicitários, entre outros, que, por meio de atividades coletivas, produzem e perpetuam a ideologia e a crença na cultura de moda. É o sistema de moda que cria as barreiras simbólicas entre o que é ou não moda, determinando qual a estética legítima do momento. Os agentes, instituições, eventos e estratégias que desenvolvem e perpetuam a cultura de moda estão sintetizados no Quadro 1.

As grifes de moda são consideradas por Godart (2009) como componentes do núcleo do sistema de moda, já que estão diretamente envolvidas na definição das tendências e ciclos do vestuário. Uma grife de moda é composta geralmente por uma equipe de estilistas ou designers. Kawamura (2005) explica que estes profissionais são considerados as 'estrelas' do sistema de moda. Os estilistas ou designers necessitam ser legitimados por outros agentes das instituições de moda, e sua reputação é confirmada ao participarem de eventos relevantes da área.

Outros profissionais de moda incluem stylists, que auxiliam os designers na interpretação de estilos e tendências, e fotógrafos, que participam da construção da identidade da marca com a produção de imagens (GODART, 2009). Também, há um conjunto de profissionais de comunicação que podem ser descritos como 'guardiões da 
moda'. Jornalistas e editores, entre outros, compõem a imprensa especializada, cuja função é avaliar as peças desenvolvidas pelas grifes e qualificar os estilos ou coleções propostos (KAWAMURA, 2005). As mídias on-line, como os weblogs, websites, e outros canais, foram assimilados pelo sistema de moda (CARVALHO, 2015). Assim, influenciadores digitais, como blogueiras que veiculam conteúdos de estilos e tendências, também exercem influência como guardiões da moda (TAVERNARI; MURAKAMI, 2012).

Quadro 1. Agenciadores de moda.

\begin{tabular}{|c|c|}
\hline Elementos & Descrições \\
\hline Grifes de Moda & $\begin{array}{l}\text { Empresas comerciais e instituições socioculturais autorizadas a atuarem como } \\
\text { fontes de estilos e produtos de Moda pelo sistema cultural e mercadológico. }\end{array}$ \\
\hline $\begin{array}{l}\text { Estilistas e } \\
\text { Designers }\end{array}$ & $\begin{array}{l}\text { Profissionais criativos já reconhecidos na economia política de Moda são } \\
\text { anunciados como "estrelas", por serem indicados como fontes da genialidade } \\
\text { necessária à mítica de Moda. }\end{array}$ \\
\hline $\begin{array}{c}\text { Imprensa } \\
\text { especializada }\end{array}$ & $\begin{array}{l}\text { Conjunto de profissionais e veículos de comunicação especializados, que } \\
\text { atestam e divulgam quais são os estilos e os produtos de Moda. }\end{array}$ \\
\hline $\begin{array}{l}\text { Profissionais de } \\
\text { Moda }\end{array}$ & $\begin{array}{l}\text { Profissionais cuja função é diretamente relacionada e reconhecida no } \\
\text { processo estético-simbólico distintivo de marcas, serviços, eventos e produtos } \\
\text { de Moda. }\end{array}$ \\
\hline Eventos de Moda & $\begin{array}{l}\text { Desfiles, lançamentos de produtos, semanas de Moda e outros eventos } \\
\text { reunindo profissionais, celebridades, críticos, clientes e consumidores de } \\
\text { Moda. }\end{array}$ \\
\hline $\begin{array}{l}\text { Calendário de } \\
\text { Moda }\end{array}$ & $\begin{array}{l}\text { Demarca e anuncia estações de Moda, lançamento de coleções, produtos e } \\
\text { datas de eventos no sistema cultural e comercial de Moda. }\end{array}$ \\
\hline Capitais da moda & $\begin{array}{l}\text { Cidades destacadas em criação de estilos, ensino, eventos, concentração de } \\
\text { produtores e comerciantes de Moda, como Paris, Londres, Nova lorque, } \\
\text { Milão. Em âmbito nacional, destacam-se São Paulo e Rio de Janeiro. }\end{array}$ \\
\hline $\begin{array}{l}\text { Fotografia de } \\
\text { Moda }\end{array}$ & $\begin{array}{l}\text { Produções fotográficas que registram ou recriam a cultura de Moda, com } \\
\text { imagens de eventos, serviços, produtos e modelos divulgadas em revistas, } \\
\text { catálogos e peças publicitárias. }\end{array}$ \\
\hline Celebridades & $\begin{array}{l}\text { Pessoas públicas e influentes na cultura de Moda, por sua condição pessoal ou } \\
\text { profissional, sendo formadoras de opinião por suas aparições, palavras, } \\
\text { atitudes e ações públicas. }\end{array}$ \\
\hline
\end{tabular}

Fonte: Schmiegelow (2016, p. 62-63).

Entre diversos eventos que reúnem profissionais, celebridades, críticos, clientes e consumidores de moda, destacam-se os desfiles, nos quais as grifes apresentam suas coleções. Vilaseca (2011, p. 16) caracteriza um desfile 
como "[...] uma ferramenta de comunicação efêmera de grande magnitude", que demanda grande investimento de tempo e de orçamento, e quando realizado de modo adequado pode gerar publicidade gratuita em revistas, jornais, weblogs e televisão.

Os desfiles são realizados em períodos específicos do ano, de acordo com o calendário de moda, que coordena o lançamento das coleções tradicionais outono/inverno e primavera/verão, bem como de outras datas que guiam a comercialização, por exemplo, de pré-coleções. Cidades como Nova Iorque, Paris, Londres e Milão sediam as mais importantes semanas de moda mundiais e são reconhecidas como capitais de referência para a moda (VILASECA, 2011). As principais cidades de referência para a moda nacional são São Paulo e Rio de Janeiro.

A fotografia, para Shinkle (2008), é considerada a força motriz do sistema de moda. A aproximação ocasional com a fotografia artística é ressaltada por Martins (2014), na qual o caráter fantasioso e narrativo é destacado, sendo o conceito trabalhado de modo tão impactante que, por vezes, a roupa passa a ser um elemento acessório da narrativa.

As marcas de moda costumam promover associações com celebridades do cinema, televisão, música, esporte, políticos, realeza, entre outros. Celebridades são pessoas influentes e exercem poder nos circuitos de moda, contribuindo para que a mensagem da marca se destaque entre a competição, além de proporcionar credibilidade à oferta (OKONKWO, 2007).

\subsection{Estratégias do Comércio de Moda Popular}

O modelo de negócios fast fashion constitui uma alternativa às tradicionais estratégias de venda prêt-à-porter e alta costura (GABRIELLI et al., 2012). Este modelo é caracterizado por uma adaptação na cadeia de fornecimento, 
de modo que produtos com conteúdo de moda são entregues nas lojas em cerca de um mês (WATSON; YAN, 2013). Assim, os novos estilos e modelos apresentados nas passarelas são rapidamente disponibilizados nos pontos de venda das lojas fast fashion (CORTEZ et al., 2014). As marcas internacionais Zara (Espanha), H\&M (Suíça), TopShop (Reino Unido) e Forever 21 (EUA) são exemplos de redes fast fashion. No âmbito de atuação nacional, destacam-se as marcas C\&A, Hering, Renner, Marisa e Riachuelo (LODI; ECHEVESTE, 2011).

As marcas fast fashion permitem aos consumidores se manterem atualizados com as tendências de moda mediante baixo investimento financeiro (GABRIELLI et al., 2013). Este modelo de negócios recebe críticas devido a ocasionais denúncias de exploração de trabalhadores terceirizados (AUDI; JUNQUEIRA, 2013), e por ser prejudicial ao meio ambiente, visto que a dinâmica imposta incentiva o descarte precipitado das peças (KIM et al., 2012). Casos de produção de peças muito similares ou mesmo cópias de marcas de grife também constituem motivos de críticas ao modelo fast fashion (FARIA, 2010).

Uma estratégia aplicada por marcas fast fashion, buscando a transferência de associação de moda, são as parceiras denominadas co-branding. Esta estratégia consta da utilização de múltiplos nomes de marca para representar e endossar um único produto (CHANG, 2009). As marcas envolvidas em uma parceria co-branding são independentes antes, durante e após a oferta do produto em conjunto, sendo esta uma estratégia proposital na qual a cooperação é perceptível pelos consumidores e o produto é comercializado com as duas marcas ao mesmo tempo (HELMIG et al., 2008).

As parcerias de co-branding das marcas fast fashion, especialmente no mercado brasileiro, costumam ser com 
marcas de grife ou designers renomados. A prática é relacionada à democratização de estilos e produtos de moda, visto que coleções de menor porte, denominadas 'coleçõescápsula', são criadas pela marca de grife e produzidas e comercializadas pela rede fast fashion. Os produtos resultantes da parceria são vendidos a preços acessíveis, e a estratégia resulta na transferência da imagem da marca de grife para os produtos da rede popular (CAETANO, 2013).

A estratégia de instalação de lojas experienciais, entre outras lojas com conceitos diferenciados, também é explorada pelas marcas fast fashion. O termo 'lojas experienciais' é usado para caracterizar diferentes formatos de lojas, cujo objetivo é proporcionar espaços privilegiados para uma relação entre produtos e clientes ou consumidores (SPENCE et al., 2014). Estes espaços são projetados por arquitetos, designers e artistas, entre outros profissionais, visando a construção de instalações de lojas especiais das marcas, que promovam experiências fascinantes aos visitantes (GENESINI, 2014).

Um dos formatos consolidados de lojas experienciais são as 'concept stores', ou, em português, 'lojas conceito'. Conforme Rexhepi (2014), este formato almeja a venda de produtos e prestação de serviços voltados a um mesmo e específico estilo de vida. Deste modo, estas lojas compõem uma experiência única para um determinado público-alvo, como a oferta de produtos e serviços exclusivos, inovadores e originais. Inclusive, as lojas conceito podem ser multimarcas. Já as 'lojas flagship' representam uma única marca, e têm como característica a localização em áreas nobres ou proeminentes, projetadas para a experimentação e venda de produtos em ambientes que se destacam pela alta qualidade para a comunicação do posicionamento e valores da marca (MANLOW; NOBBS, 2013). 


\section{MARCAS POPULARES E REPOSICIONAMENTO DE MODA}

De maneira geral, houve o reposicionamento das marcas populares do varejo de vestuário e acessórios, buscando reforçar sua associação com a cultura e o conceito de moda. Para tanto, foi necessário um conjunto de adaptações nas expressões da marca, nas informações e nos anúncios publicitários de produtos e ações que, publicamente, são representados pela marca. As associações, estratégias, recursos e ações de reposicionamento das marcas C\&A, Lojas Renner, Marisa e Riachuelo (Quadro 2), estão descritas nesta seção. Estas incluem a adoção do modelo fast fashion, a reprodução de elementos e comportamentos semelhantes aos das marcas de grife, bem como a aplicação de estratégias próprias desenvolvidas pelas marcas populares, que buscam a associação com diversos elementos do sistema de moda (SCHMIEGELOW, 2016). 
Quadro 2. Associações e estratégias de reposicionamento.

\begin{tabular}{|c|c|c|}
\hline ASSOCIAÇÃO & ESTRATÉGIAS, RECURSOS E AÇÕES & MARCA \\
\hline $\begin{array}{l}\text { Grifes de Moda, } \\
\text { profissionais, celebridades }\end{array}$ & $\begin{array}{l}\text { Co-branding, endosso público, identidade e } \\
\text { publicidade comum, coleções-cápsula. }\end{array}$ & C\&A, Riachuelo \\
\hline \multirow{3}{*}{$\begin{array}{l}\text { Imprensa especializada: } \\
\text { editores de Moda, } \\
\text { jornalistas, blogueiros }\end{array}$} & Participação e cobertura de eventos da marca. & $\begin{array}{l}\text { C\&A, Lojas Renner, } \\
\text { Marisa, Riachuelo }\end{array}$ \\
\hline & Parcerias. & C\&A, Marisa, Riachuelo \\
\hline & Produção das próprias revistas de Moda. & $\begin{array}{l}\text { C\&A, Lojas Renner, } \\
\text { Marisa, Riachuelo }\end{array}$ \\
\hline \multirow{2}{*}{$\begin{array}{l}\text { Profissionais de Moda: } \\
\text { modelos, fotógrafos, } \\
\text { cabelereiros, } \\
\text { maquiadores, stylists }\end{array}$} & Contratação de profissionais de Moda conceituados. & $\begin{array}{l}\text { C\&A, Lojas Renner, } \\
\text { Riachuelo }\end{array}$ \\
\hline & $\begin{array}{l}\text { Contratação de modelos famosos para campanhas } \\
\text { publicitárias ou desfiles. }\end{array}$ & C\&A, Riachuelo \\
\hline \multirow{5}{*}{$\begin{array}{l}\text { Realização de desfiles, } \\
\text { patrocínio ou participação } \\
\text { em semanas de Moda }\end{array}$} & $\begin{array}{l}\text { Patrocínio e ações em eventos conceituados (SPFW } \\
\text { e FR). }\end{array}$ & C\&A, Riachuelo \\
\hline & $\begin{array}{l}\text { Apresentação de coleções-cápsula em co-branding } \\
\text { em evento conceituado (SPFW). }\end{array}$ & Riachuelo \\
\hline & Participação em eventos regionais. & $\begin{array}{l}\text { C\&A, Lojas Renner, } \\
\text { Marisa, Riachuelo }\end{array}$ \\
\hline & $\begin{array}{l}\text { Desfiles em eventos próprios ou inaugurações de } \\
\text { lojas. }\end{array}$ & $\begin{array}{l}\text { C\&A, Lojas Renner, } \\
\text { Marisa, Riachuelo }\end{array}$ \\
\hline & Campanhas audiovisuais com modelos desfilando. & $\begin{array}{l}\text { C\&A, Lojas Renner, } \\
\text { Marisa, Riachuelo }\end{array}$ \\
\hline Calendário de Moda & $\begin{array}{l}\text { Coleções e pré-coleções outono/inverno e } \\
\text { primavera/verão. } \\
\text { Divulgação da inspiração e conceito de cada coleção. }\end{array}$ & $\begin{array}{l}\text { C\&A, Lojas Renner, } \\
\text { Marisa, Riachuelo }\end{array}$ \\
\hline Capitais da moda & $\begin{array}{l}\text { Referência das tendências de Moda das capitais em } \\
\text { weblogs ou redes sociais. }\end{array}$ & Riachuelo, Renner \\
\hline \multirow{2}{*}{ Fotografia de Moda } & Disseminação da estética fotográfica de Moda. & $\begin{array}{l}\text { C\&A, Lojas Renner, } \\
\text { Marisa, Riachuelo }\end{array}$ \\
\hline & $\begin{array}{l}\text { Cenas de campanhas que simulam ensaios } \\
\text { fotográficos. }\end{array}$ & $\begin{array}{l}\text { C\&A, Lojas Renner, } \\
\text { Marisa, Riachuelo }\end{array}$ \\
\hline \multirow{2}{*}{ Celebridades } & $\begin{array}{l}\text { Associação (eventos, desfiles, campanhas } \\
\text { publicitárias). }\end{array}$ & $\begin{array}{l}\text { C\&A, Lojas Renner, } \\
\text { Marisa, Riachuelo }\end{array}$ \\
\hline & $\begin{array}{l}\text { Coleções-cápsula em parceria (cantoras, blogueiras, } \\
\text { personalidades). }\end{array}$ & C\&A, Marisa, Riachuelo \\
\hline \multirow{2}{*}{$\begin{array}{l}\text { Sofisticação, elegância, } \\
\text { distinção }\end{array}$} & Renovação do ponto de venda /lojas diferenciadas. & $\begin{array}{l}\text { C\&A, Lojas Renner, } \\
\text { Marisa, Riachuelo }\end{array}$ \\
\hline & Lojas experienciais - Flagship ou Loja-conceito. & C\&A, Riachuelo \\
\hline \multirow{4}{*}{$\begin{array}{l}\text { Disseminação informativa } \\
\text { ou didática do } \\
\text { conhecimento de Moda }\end{array}$} & $\begin{array}{l}\text { Comunicação das tendências de Moda em websites, } \\
\text { weblogs e redes sociais, com opções de produtos. }\end{array}$ & $\begin{array}{l}\text { C\&A, Lojas Renner, } \\
\text { Marisa, Riachuelo }\end{array}$ \\
\hline & $\begin{array}{l}\text { Disseminação de termos, expressões ou gírias de } \\
\text { Moda. }\end{array}$ & $\begin{array}{l}\text { C\&A, Lojas Renner, } \\
\text { Marisa, Riachuelo }\end{array}$ \\
\hline & $\begin{array}{l}\text { Patrocínio ou participação em eventos informativos } \\
\text { ou programas televisivos sobre Moda. }\end{array}$ & $\begin{array}{l}\text { C\&A, Lojas Renner, } \\
\text { Marisa, Riachuelo }\end{array}$ \\
\hline & $\begin{array}{l}\text { Consultoria online e em lojas físicas, instalações } \\
\text { itinerantes, conselhos, palestras, workshops. }\end{array}$ & $\begin{array}{l}\text { C\&A, Lojas Renner, } \\
\text { Marisa, Riachuelo }\end{array}$ \\
\hline
\end{tabular}

Fonte: Schmiegelow (2016, p. 120-121).

A comercialização de peças que traduzem as últimas tendências, principal argumento das redes fast fashion para serem publicamente reconhecidas como marcas de moda, é acompanhada de uma série de estratégias de comunicação pública que visam a disseminação informativa ou didática do conhecimento de moda. É comum observar nos websites, weblogs, e redes sociais oficiais das marcas a veiculação de 
conteúdos voltados a indicar ao usuário quais as tendências de moda do período. Por vezes, a tendência é legitimada por meio de menção à grife ou ao designer que a lançou, semana de moda ou revista em que foi divulgada, ou celebridades que usaram o estilo. O emprego de um conjunto de palavras, gírias ou expressões da cultura de moda também é comumente verificado no discurso das marcas populares.

Aliada à estratégia de divulgação das tendências, as redes de fast fashion oferecem ao público dicas, conselhos ou consultoria de moda. Isto é feito por meios digitais ou físicos, com postagens em weblogs e redes sociais, em aplicativos, lojas ou espaços itinerantes das marcas. Geralmente, a credibilidade das dicas, conselhos ou consultoria se efetiva por meio da participação de especialistas do ramo da moda, como stylists, influenciadores digitais, ou profissionais da imprensa. A disseminação da cultura de moda entre os consumidores também é feita em workshops, palestras, ou conversas com designers, stylists ou personalidades de moda, promovidas pelas marcas.

As diferentes posições ocupadas no sistema de moda pelas marcas de grife e redes de fast fashion, especialmente no que diz respeito ao ciclo das tendências de moda, influenciam nas estratégias de posicionamento das marcas populares. Enquanto as marcas de grife participam como lançadoras de tendências de moda, o modelo de negócios fast fashion caracteriza-se por disponibilizar rapidamente ao consumidor peças baseadas nos estilos já apresentados nas passarelas e legitimados na imprensa especializada como tendência.

Deste modo, verifica-se que parte das convenções seguidas pelas marcas de grife não podem ser reproduzidas pelas marcas populares. Portanto, em princípio, as redes fast 
fashion não empregam designers renomados ou apresentam suas coleções nas semanas de moda mais relevantes, além de, tradicionalmente, não serem as referências principais para a imprensa de moda. Para superar este obstáculo, as redes fast fashion desenvolveram modos diferenciados de se relacionarem com estes agentes, eventos e instituições de moda, constituindo uma série de estratégias próprias deste segmento de mercado.

As marcas C\&A e Riachuelo, através da prática de co-branding, promovem associações com grifes de moda e designers renomados por meio de coleções-cápsula em parceira. Isto possibilita que, ao menos ocasionalmente, as redes fast fashion possam ofertar produtos desenvolvidos pelos designers reconhecidos como as 'estrelas' do mundo da moda. Como consequência, os produtos destas coleções-cápsula são diretamente credenciados como produtos de moda, e a imagem das marcas populares é beneficiada positivamente pela associação. O envolvimento de grifes e designers renomados no co-branding, eventualmente, resulta em repercussão na mídia especializada. Portanto, trata-se também de um meio para as marcas populares serem divulgadas na imprensa de moda.

Acerca das semanas de moda de maior prestígio nacional, as marcas populares buscaram atuar como patrocinadoras de determinadas edições. Este recurso, aplicado pela C\&A e Riachuelo, além do apelo básico da marca ser divulgada como patrocinadora, inclui uma série de ações durante o evento, como a instalação de um ambiente temático e cobertura do evento nos websites e redes sociais das redes. Deste modo, posicionam-se perante os consumidores como atentas às tendências de moda, inseridas nos eventos responsáveis pelo lançamento das tendências. Outra forma de inserção nas semanas de moda, verificada como estratégia da Riachuelo, foi a apresentação 
de coleções-cápsula em parceria com grifes nacionais ou internacionais no SPFW.

Há, entretanto, convenções do sistema de moda que podem ser reproduzidas pelas marcas populares. Destas, destacam-se a contratação de profissionais de moda, a disseminação da estética fotográfica de moda, e a associação com celebridades. A contratação eventual de profissionais de moda é voltada à produção de campanhas publicitárias, desfiles ou revistas próprias das marcas. Ao divulgar a qualidade dos profissionais de moda envolvidos na produção, as marcas e os produtos comercializados são valorizados. Entre os profissionais de moda, os gestores das marcas C\&A e Riachuelo costumam contratar modelos, reconhecidos pela participação em campanhas para grifes de moda, para atuar em suas campanhas publicitárias fotográficas ou audiovisuais.

As imagens publicitárias veiculadas pelas marcas populares, em geral, buscam reproduzir a visualidade da fotografia de moda, apresentando modelos em poses características da cultura de moda, bem como trabalhando com conceitos que sugerem uma narrativa, por exemplo. Algumas campanhas publicitárias da marca Riachuelo foram produzidas em outros países, evidenciando um alto investimento e valorizando as coleções e a imagem da marca.

A associação com celebridades, no contexto das marcas estudadas, é feita geralmente com atores reconhecidos nacionalmente, sendo também verificadas ações com artistas do mundo da música e influenciadores digitais. As ações incluem a participação das celebridades em eventos, como inaugurações de loja ou lançamento de coleções, e atuação como modelos para a marca. A prática de co-branding com artistas do mundo da música e outras personalidades resulta em coleções baseadas no estilo da 
personalidade em questão, que também participa das ações publicitárias de divulgação.

Enfim, foi verificada uma série de ações voltadas à valorização dos pontos de venda e produtos expostos. Todas as marcas alteraram o layout dos pontos de venda, visando a alteração da percepção dos consumidores em relação aos produtos comercializados e sofisticação das instalações. A nova apresentação dos produtos passou a ser feita por estilos ou tendências, destacando as possibilidades de composições de looks completos.

Ainda sobre o ponto de venda, foram inauguradas várias lojas diferenciadas. A diferenciação pode ser relacionada a gama de produtos ofertados (por exemplo, lojas exclusivamente femininas), ambientação ou conceito (como lojas sustentáveis) ou localização privilegiada do ponto de vista socioeconômico. As marcas C\&A e Riachuelo também estabeleceram lojas experienciais, caracterizadas como 'flagship' ou 'loja-conceito'. Estas lojas passaram a ser o local de eventos variados promovidos pelas marcas, que reúnem celebridades e profissionais do mundo da moda. As lojas especiais e renovadas colaboram para 0 posicionamento almejado pelas marcas populares ao sugerir conceitos de sofisticação, elegância e distinção, valores tradicionalmente coerentes com a cultura de moda.

\section{RESULTADOS}

A seção anterior descreveu as principais estratégias para o reposicionamento das marcas C\&A, Lojas Renner, Marisa e Riachuelo como marcas populares de moda. Analisando o conjunto de informações, foi verificado que estas podem ser estruturadas em três estratégias básicas e específicas para a associação comercial de marcas populares do segmento de vestuário e acessório com o sistema cultural e o conceito de 
moda: (1) adoção do modelo de produção fast fashion; (2) estratégia de co-branding e de outras associações aos elementos, agentes e instituições do sistema de moda; e (3) estratégia de investir em lojas especiais, desde apenas lojas mais sofisticadas em locais privilegiados até a criação e construção de lojas experienciais.

Cada uma dessas estratégias básicas é desenvolvida a partir de uma série de ações complementares, que apesar de apresentarem variações entre as marcas populares de moda, são praticamente recorrentes. Assim, configura-se uma sistematização das estratégias de reposicionamento de moda em marcas populares, nas quais as diversas ações complementares suportam as três ações básicas que, em interação, promovem a associação com moda. As estratégias básicas e suas ações de suporte estão sintetizadas no Quadro 3 e são detalhadas a seguir.

A primeira estratégia, o modelo fast fashion, requer como ações, inicialmente, a adoção de um sistema com processos e ações muito dinâmicas de produção, distribuição e venda de produtos que, também, permitam a comunicação dos funcionários com os clientes e com as equipes de criação dos produtos. É necessária a comercialização de coleções outono/inverno e primavera/verão de acordo com o calendário oficial de moda, bem como de pré-coleções e das mini-coleções características do sistema fast fashion. Na comunicação com o público, é destacada a inspiração ou conceito do desenvolvimento dos produtos. 
Quadro 3. Sistematização de estratégias de reposicionamento de marca popular de Moda.

\begin{tabular}{|c|c|}
\hline Estratégia Básica & Ações complementares \\
\hline \multirow[t]{6}{*}{$\begin{array}{l}\text { Adoção do Modelo Fast } \\
\text { Fashion }\end{array}$} & $\begin{array}{l}\text { Processos dinâmicos de produção, distribuição e comunicação } \\
\text { entre funcionários, clientes e equipes de criação. }\end{array}$ \\
\hline & $\begin{array}{l}\text { Comercialização de coleções e pré-coleções de acordo com o } \\
\text { calendário de Moda, além das mini-coleções típicas do fast fashion. }\end{array}$ \\
\hline & $\begin{array}{l}\text { Comunicação digital (websites, weblogs, redes sociais) para } \\
\text { interação com clientes e agentes do sistema de Moda (jornalistas, } \\
\text { inlfuenciadores digitais). }\end{array}$ \\
\hline & Disseminação didática de informações de Moda. \\
\hline & Consultoria de Moda em ambientes físicos ou digital. \\
\hline & $\begin{array}{l}\text { Campanhas publicitárias com ênfase na oferta de produtos com } \\
\text { informação de Moda e na facilidade financeira. }\end{array}$ \\
\hline \multirow{4}{*}{$\begin{array}{l}\text { Co-branding e associações com } \\
\text { elementos e agentes do } \\
\text { sistema de Moda }\end{array}$} & $\begin{array}{l}\text { Identificação e seleção de oportunidades de associações com } \\
\text { agente ou instituições de Moda. }\end{array}$ \\
\hline & $\begin{array}{l}\text { Efetivação da associação e divulgação pública (coleções cápsula, } \\
\text { campanhas publicitárias). }\end{array}$ \\
\hline & $\begin{array}{l}\text { Desenvolvimento de identidade visual, ações de relacionamento, } \\
\text { assessoria de imprensa e publicidade para a parceria. }\end{array}$ \\
\hline & $\begin{array}{l}\text { Cocriação, participação, apoio ou patrocínio de eventos diversos de } \\
\text { Moda. }\end{array}$ \\
\hline \multirow[t]{4}{*}{$\begin{array}{l}\text { Investimento em lojas } \\
\text { especiais }\end{array}$} & $\begin{array}{l}\text { Identificação e seleção de locais socialmente e comercialmente } \\
\text { diferenciados. }\end{array}$ \\
\hline & $\begin{array}{l}\text { Projetação de ambientes sofisticados, ou com o conceito almejado } \\
\text { para a loja em particular. }\end{array}$ \\
\hline & $\begin{array}{l}\text { Investimento em visual merchandising para valorizar a organização } \\
\text { e exposição de produtos. }\end{array}$ \\
\hline & Programação de eventos de diversas naturezas na loja. \\
\hline
\end{tabular}

Fonte: Elaborado pelos autores.

Seguindo, é mantido um amplo sistema de comunicação eletrônico digital, com website oficial da marca constantemente atualizado, pelo menos um weblog interativo atuando como um clube de relacionamento com clientes e redes sociais. Além disso, é necessário interagir nestas mídias com outras fontes de informação e comunicação de moda, como influenciadores digitais independentes e jornalistas especializados.

Os recursos humanos e tecnológicos devem atuar como bases de ações informativas para o diálogo sobre moda e a 
disseminação de informação de moda, visando promover o interesse e a atualização dos clientes. As informações divulgadas devem disseminar as tendências de moda, em especial as aplicadas nos produtos da marca, e utilizar expressões características da cultura da moda. É de interesse também referenciar eventos renomados e capitais da moda.

É oferecida a prestação de consultoria de moda, realizada eventualmente nas lojas e em eventos públicos especiais ou comumente oferecida através da mídia digital. Além das ações de relacionamento com o público já assinaladas, as campanhas publicitárias comunicam continuamente 0 posicionamento como marca de moda fast fashion, bem como utilizar a estética fotográfica ou campanhas audiovisuais com características da cultura de moda. Também são destacadas nas campanhas as facilidades de acesso às constantes novidades, por meio de preços acessíveis e do uso do cartão de crédito da marca ou do crediário da empresa.

Para desenvolver a estratégia básica de co-branding e de outras associações com elementos, agentes e instituições do sistema de moda, são efetuadas ações iniciais como identificação e seleção de oportunidades de eventual associação com marcas de grife e designers, ou contratação temporária de modelo, ator, atriz ou celebridade de destaque junto ao público de interesse. Estas são seguidas por ações que efetivem legalmente, praticamente e publicamente a associação com a marca de grife, com o profissional ou com a celebridade escolhida. Por exemplo, a produção e a apresentação pública de produtos de comunicação e de Moda que caracterizam e representam as 'coleções-cápsula'.

Detalhando a proposição anterior, há outras ações práticas para associar publicamente a marca popular de 
moda com a grife, o profissional ou a celebridade parceira. São necessárias ações de planejamento e produção de um sistema de identidade visual especialmente produzido para representar particularmente a ação de co-branding, associando a marca popular de moda com a marca e a imagem pública da entidade parceira. Isso também requer outras ações de relacionamento, assessoria de imprensa e publicidade específicas, para publicitar a parceria resultante da estratégia de co-branding.

Há outras ações eventuais que associam as marcas populares de moda com eventos de moda de diversas amplitudes, sendo essas decorrentes de cocriação, participação, apoio ou patrocínio das marcas populares de moda em eventos regionais, nacionais ou internacionais de moda.

Finalmente, para desenvolver a estratégia básica de investimento em lojas especiais, renovadas ou experienciais, de maneira geral, são tomadas ações de identificação e seleção de locais socialmente e comercialmente diferenciados para a instalação das lojas especiais ou experienciais. Posteriormente, é projetada a estrutura arquitetônica e de mobiliário para a criação de um ambiente sofisticado. No caso de lojas especiais ou experienciais, a projetação deve ser feita visando à criação do conceito específico almejado para a loja.

Ainda, são tomadas ações para a criação e a produção de elementos de visual merchandising para a comunicação publicitária-comercial, valorizando ainda a organização e a apresentação dos produtos. As lojas especiais são exploradas com o planejamento, preparação e realização de uma programação continuada de exposições, promoções e eventos para dinamizar a existência e a atuação da loja especial. 


\section{CONSIDERAÇÕES FINAIS}

Uma marca, como um conjunto expressivo associado a um conjunto significativo, compreende uma série de sinais físicos que, ao serem contemplados pelo público, expressam sensações, sentimentos e ideias, estabelecendo a imagem de marca. Os produtos, preços, o ambiente das lojas, campanhas publicitárias, e demais ações das marcas populares, tradicionalmente, compõem um conjunto expressivo que desencadeia no público consumidor a imagem de redes de lojas com produtos de vestuário e acessórios de qualidade, comercializados a preços acessíveis.

No momento em que os gestores das marcas populares de vestuário identificaram que a associação com a cultura de moda era de interesse de seus consumidores, estabeleceram uma série de estratégias para alterar o conjunto expressivo destas marcas, a fim de reforçar o conceito de moda na imagem já consolidada. Isso representou um reposicionamento de marca, realizado gradualmente por diversas redes de lojas de diferentes portes.

A descrição das estratégias, ações, discursos e recursos aplicados pelas marcas de atuação nacional C\&A, Lojas Renner, Marisa e Riachuelo apontou diversas similaridades, que evidenciaram a possibilidade de configuração de uma sistematização das estratégias de reposicionamento de redes de lojas deste segmento em marcas populares de moda. Os resultados apontaram três estratégias básicas: de adoção do sistema fast fashion, prática de co-branding e associação com elementos do sistema de moda, e investimento em lojas especiais; assim como uma série de ações que as suportam e, em interação, possibilitam o posicionamento das marcas populares de moda. 
É possível antecipar que com a constante evolução da cultura de moda, eventualmente, novas oportunidades de associação serão aplicadas pelas marcas populares de moda, bem como outras serão descontinuadas. Algo a ser considerado em estudos futuros é o sistema fast fashion como uma das bases do posicionamento de moda. Este sistema é criticado devido aos fatores sociais, ambientais e de propriedade intelectual. Assim, caso as ações tomadas pelas marcas fast fashion para reduzir o impacto negativo destas críticas não sejam suficientes, a associação com este modelo de produção pode se tornar prejudicial a ponto de requerer revisões no posicionamento atual das marcas populares de moda.

\section{APOIO}

O presente trabalho foi realizado com apoio da Coordenação de Aperfeiçoamento de Pessoal de Nível Superior - Brasil (CAPES) - Código de financiamento 001.

\section{REFERÊNCIAS}

AAKER, D. On branding: 20 princípios que decidem o sucesso das marcas. Porto Alegre: Bookman, 2015.

AUDI, T.; JUNQUEIRA, C. No mundo da moda: notas sobre o mercado de luxo e o mercado fast fashion. Inter Relações, v.13, n.38, p. 24-28, 2013. Disponível em:

http://www.faculdadesantamarcelina.com.br/jornal/index.ph p/InterRelacoes/article/view/7. Acesso em: 3 out. 2016.

BRIDI, L. S.; PERERA, A. A. Reposicionamento de mercado: estudo de caso das Lojas Pompéia. In: XXXVII Congresso Brasileiro de Ciências da Comunicação, 2014, Foz do Iguaçu.

Anais XXXVII Intercom. São Paulo, p. 1-14, 2014.

CAETANO, Carolina Carpintelli. O cross-branding e a cocriação no âmbito do varejo de moda. São Paulo, 2013. Dissertação (Mestrado em Ciências) - Programa de Pós-graduação em Têxtil e Moda da Escola de Artes, Ciências e Humanidades da Universidade de São Paulo, 2013. 
CARVALHO, P. R. A liderança de opinião nas dinâmicas da moda: a blogueira-celebridade e sua representação identitária. In: XIV Congresso Internacional de Comunicação Ibercom 2015, Escola de Comunicações e Artes/USP, São Paulo. Anais do XIV Ibercom, São Paulo, p. 2145-2156, 2015. Disponível em:

http://www.assibercom.org/download/Ibercom_2015_Anais _Completo.pdf. Acesso em: 30 set. 2016.

CHANG, W. L. Roadmap of co-branding positions and strategies. The Journal of American Academy of Business, Cambridge, v. 15, n.1, p.77-84, 2009. Disponível em: http://mail.tku.edu.tw/wlchang/JAABC09.pdf. Acesso em: 9 maio 2016.

CORTEZ, M. A.; TU, N. T.; ANH, D. V.; ZAGITAHNG, B.; VEGAFRIA, E. Fast fashion Quadrangle: An analysis.

Academy of Marketing Studies Journal, v.18, n.1, p. 118, 2014. Disponível em:

http://www.alliedacademies.org/articles/amsjvol18no12014. pdf. Acesso em: 8 maio 2016.

\section{CRUZ-MOREIRA, Juan R. Industrial Upgrading nas}

cadeias produtivas globais: reflexões a partir das indústrias têxtil e do vestuário de Honduras e do Brasil. São Paulo, 2003. Tese (Doutorado em Engenharia), Escola politécnica da Universidade de São Paulo. Departamento de Engenharia de Produção, São Paulo, 2003.

ENTWISTLE, J. The fashioned body: fashion, dress and social theory. Cambridge: Polity Press, 2015.

EUZÉBIO, K. M.; VIEIRA, S. M.; PERASSI, R. L. S. Gestão do design e informação visual nos sítios digitais: as marcas de moda sul catarinenses na internet. DAPesquisa, n.9, v.9, p. 411-428, 2011.

FRANKE, G. A moda e o vestir sobre a perspectiva do popular: um estudo sobre o comportamento e a percepção de consumidores de um shopping popular sobre moda e consumo de vestuário. Dissertação (Mestrado em Sociologia), 2011. Programa de Pós-Graduação em Sociologia, Instituto de Filosofia e Ciências Humanas UFRGS, 2011.

GABRIELLI, V.; BAGHI, I. ; CODELUPPI, V. Consumption practices of fast fashion products: a consumer-based approach. Journal of Fashion Marketing and Management, v.17, n.2, p. 206-224, 2013. Disponível em: 10.1108/JFMM-10-2011-0076. Acesso em: 4 set. 2016.

GARCIA, A. E. G. Longevidade em organizações

empresariais brasileiras: o caso das Lojas Renner S.A. 
2011. 311 f. Tese (Doutorado em Administração) Programa de Pós-Graduação em Administração, Universidade do Vale do Rio dos Sinos, São Leopoldo, RS, 2011.

GEARGEOURA, L. J.; MORIGUCHI, S. N. Formatação de lojas-símbolo no varejo de luxo: tradição ou inovação? Das antigas maisons às modernas lojas-conceito e flagships. In: $6^{\circ}$ Congresso do Instituto Franco-brasileiro de Administração de Empresas - IFBAE, 2011, Franca. Anais do $6^{\circ}$

Congresso IFBAE, 2011. Disponível em:http://www.ifbae.com.br/congresso6/pdf/07.pdf. Acesso em: 13 maio 2016.

GENESINI, L. Espaços Interativos: o design de experiência em marcas e concept stores. São Paulo: InVersos, 2014.

GODART, F. C. Status and Style in Creative Industries: the case of the fashion system. Dissertação (submetida como requerimento parcial para o grau de doutor em filosofia) - Graduate School of Arts and Sciences, Columbia University, 2009. Disponível em:

http://gradworks.umi.com/33/73/3373738.html. Acesso em: 2 set. 2016.

HELMIG, B.; HUBER, J. A.; LEEFLANG, P. S. H. Co-branding: the state of the art. Schmalenbach Business Review, v.60, n.4, p. 359-377, 2008. Disponível em:

http://papers.ssrn.com/sol3/papers.cfm?abstract_id $=99347$ 0. Acesso em: 9 maio 2016.

KAWAMURA, Y. Fashion-ology: an introduction to fashion studies. Oxford: Berg, 2005.

KAPFERER, J. N. The new strategic brand management: creating and sustaining brand equity long term. London/Philadelphia: Kogan page, 2008.

KIM, H.; CHOO, H. J.; YOON, N. The motivational drives of fast fashion avoidance. Journal of Fashion Marketing and Management, v.17, n.2, 2013. pp. 243-290. Disponível em:10.1108/JFMM-10-2011-0070. Acesso em: 4 set. 2016.

LODI, R.; ECHEVESTE, M. E. S. Melhorias no processo de desenvolvimento de produto de uma indústria do vestuário do segmento fast fashion. In: $8^{\circ}$ Congresso Brasileiro de Gestão de Desenvolvimento de Produto - CBGDP, 2011, Porto Alegre, RS. Anais do $8^{\circ}$ CBGDP, Porto Alegre, 2011. pp. 1-12. Disponível em:http://www.ufrgs.br/cbgdp2011/downloads/10096.pdf. Acesso em: 10 maio 2016.

LOJAS RENNER. Disponível em:

http://www.lojasrenner.com.br/. Acesso em: 31 mar. 2016. 
MANLOW, V.; NOBBS, K. Form and function of luxury flagships: an international exploratory study of the meaning of the flagship store for managers and costumers. Journal of Fashion Marketing and Management, v. 17, n. 1, p. 49-64, 2013. Disponível em: http://www.emeraldinsight.com/doi/full/10.1108/136120213 11305137. Acesso em: 13 maio 2016.

MARTINS, V. A. R. Criação e promoção: o editorial como promotor da moda. 2014. 128 f. Dissertação (Mestrado em Design de Vestuário e Têxtil) - Faculdade de Arquitetura da Universidade Técnica de Lisboa, Escola Superior de Artes Aplicadas do Instituto Politécnico de Castelo Branco, Lisboa, 2014.

MESSIAS, E. M. Stella McCartney para C\&A; Roberto Cavalli para C\&A: A Construção do Discurso da C\&A em torno de uma Moda Global Acessível. In: $11^{\circ}$ Colóquio de Moda - 8a Edição Internacional, 2015, Curitiba, PR. Anais do $11^{\circ}$ Colóquio de Moda, 2015, p. 1-12. Disponível em: http://www.coloquiomoda.com.br/anais/anais/11-Coloquiode-Moda_2015/ARTIGOS-DE-GT/GTO2-CONSUMO-DEMODA/GT-2-STELLA-MCCARTNEY-PARA-C_A.pdf. Acesso em: 30 maio 2016.

OKONKWO, U. Luxury fashion branding: trends, tactics, techniques. New York: Palgrave Macmillan, 2007.

PERASSI, R. L. S. Comunicação e Conhecimento da marca das organizações. Texto didático. Florianópolis, EGC/UFSC, 2015.

\section{REIS, L. B. A comunicação do ambiente de varejo popular sob a influência da sedução estética:}

percepções sobre a rede lojas Marisa. Tese (Doutorado em Comunicação Social) - Pontifícia Universidade Católica do Rio Grande do Sul, Faculdade de Comunicação Social, Porto Alegre, 2012.

REXHEPI, G. The concept of concept stores: a Qualitative Research on a New Retailing Concept. 2014. 64 f. Master Thesis - Erasmus School of History, Culture and Communication, Erasmus University Rotterdam, 2014. Disponível em: https://thesis.eur.nl/pub/18014/. Acesso em: 14 maio 2016.

RIES, A.; TROUT, J. Posicionamento: a batalha por sua mente. São Paulo: M. Books do Brasil, 2009.

SCALFI, V. B.; BARRIZZELLI, N. Estratégias de moda com a ascensão da classe C: um estudo exploratório. In: $\mathbf{X V}$ SemeAd - Seminários em Administração, 2012. Disponível em: 
http://sistema.semead.com.br/15semead/resultado/trabalho sPDF/346.pdf. Acesso em: 10 dez. 2016.

SCHETTINO, P. B. C.; MAIA, F. J. S. Análise do posicionamento da marca Riachuelo: a democratização da moda como perspectiva de comunicação e marketing. In: XII Congreso Latinoamericano de Investigadores de la Comunicación - ALAIC 2014, p. 1-15

SHINKLE, E. Fashion as photograph: viewing and reviewing images of fashion. London/New York: I. B. Tauris, 2008.

SILVA, A. M. Guararapes Confecções S.A: da empresa familiar ao grupo econômico. 2011. Tese (Doutorado em Ciências Sociais) - Programa de Pós-Graduação em Ciências Sociais, UFRN, Natal, 2011.

SCHMIEGELOW, S. S. A disseminação do conhecimento de moda nas marcas populares de vestuário e acessórios. 2016. Dissertação (Mestrado em Engenharia e Gestão do Conhecimento) - Programa de Pós-Graduação em Engenharia e Gestão do Conhecimento, UFSC, Florianópolis, 2016.

SEMPRINI, Andrea. A marca pós-moderna: poder e fragilidade da marca na sociedade contemporânea. São Paulo: Estação das Letras, 2006.

SPENCE, C.; PUCCINELLI, N. M.; GREWAL, D.; ROGGEVEEN, A. L. Store Atmospherics: A Multisensory Perspective.

Psychology and Marketing, v.31, n.7, p.472-488, 2014. Disponível em:

http://onlinelibrary.wiley.com/doi/10.1002/mar.20709/epdf. Acesso em: 19 maio 2016.

TAVERNARI, M. D. D.; MURAKAMI, M. H. O gênero dos Fashion Blogs: representações e autenticidades da moda e do feminino. Rumores, v.6, n.2, p. 85-106, jul-dez 2012. Disponível em:

http://www.revistas.usp.br/Rumores/article/view/55294/589 18. Acesso em: 30 set. 2016.

TELLES, R. Posicionamento e reposicionamento de marca: uma perspectiva estratégica e operacional dos desafios e riscos. 2004. $204 \mathrm{f}$. Tese (Doutorado em Administração) - Faculdade de Economia, Administração e Contabilidade, Universidade de São Paulo, São Paulo, 2004.

TUBAKI, M. L. M.; LIMA, V. C. G. A chegada da Forever 21 representa um Ponto de Virada no mercado das Lojas Riachuelo? 2014. 172 f. Monografia (Bacharel em Publicidade e Propaganda) - Curso de Comunicação Social, Universidade de Brasília, Brasília, 2014. 
VILASECA, E. Como fazer um desfile de moda. São Paulo: Senac, 2011.

WATSON, M. Z.; YAN, R. An exploratory study of the decision processes of fast versus slow fashion consumers. Journal of Fashion Marketing and Management, v.17, n.2, p. 141-159, 2013. Disponível em: http://dx.doi.org/10.1108/JFMM-02-2011-0045. Acesso em: 21 nov. 2015. 